\title{
Future of Business Models in Manufacturing
}

\author{
Johannes Seidel, Ana-Paula Barquet, Günther Seliger \\ and Holger Kohl
}

\begin{abstract}
In order to achieve systematic change in pursuit of sustainable manufacturing, both a strategic long-term perspective employing methods from future studies and a concrete implementation of the knowledge gained in sustainable business models are necessary. In this chapter, the concepts and exemplary methods for sustainable business model innovation are introduced with a special focus on sustainable manufacturing. Circular Economy-based business models and Product Service Systems are explained as examples of sustainable business models, along with a deduction of sustainability factors for both examples. The fruitful combination of future studies and sustainable business model development is illustrated in the example of a so-called living factory, a modular and adaptive production environment which integrates aspects of Circular Business Models and Product Service Systems.
\end{abstract}

Keywords Sustainable business models - Circular economy • Product service systems • Manufacturing scenarios

J. Seidel $(\bowtie) \cdot$ A.-P. Barquet $\cdot$ H. Kohl

Institute for Machine Tools and Factory Management,

Technische Universität Berlin, Pascalstrasse 8-9, 10587 Berlin, Germany

e-mail: seidel@mf.tu-berlin.de

G. Seliger

Chair of Assembly Technology and Factory Management, Institute for Machine-tools and Factory Management, Technische Universität Berlin, Berlin, Germany

(C) The Author(s) 2017

R. Stark et al. (eds.), Sustainable Manufacturing, Sustainable Production,

Life Cycle Engineering and Management, DOI 10.1007/978-3-319-48514-0_10 


\section{Introduction}

Bringing the topics of business models, future studies and sustainability research together, this chapter puts itself in a relatively new tradition of manufacturing science. Since the 1990s, the literature in the three fields mentioned above has been growing indeed, yet opportune combinations of them so far remain rare. This being the aim of this text, short introductions into each field will be made, so that existing literature can be conveniently linked to our own contributions to research on sustainable business models and future studies.

Given the challenges which current modes of production and consumption place on nature and society, it seems necessary to pursue a new way of conducting business. Transforming business models into sustainable business models and creating pathways for sustainable technology development thus constitute the main themes of this chapter. In Sect 2, a short introduction of the inner-workings and benefits of sustainable business model concepts and tools will be given, before two specific examples, namely Product Service System-based and Circular Economy-based business models will be elaborated on. A special focus will lie on the analysis of sustainability factors for those two cases. Section 3 focuses on the tools for creating successful sustainable business models drawing on findings from the area of scenario planning as an instrument of future studies. This last chapter also presents the Living Factory as an exemplary result of combining future studies with business model innovation.

\section{Sustainable Business Models}

In the simplest terms, the concept of business models can be explained by splitting the term into its components. A business can be seen as the activity of buying and selling goods and services for the purpose of earning money, while a model is a means of representing reality in a structured, simplified and intelligible manner. A business model can ergo be understood as a structured, simplified and intelligible representation of how a company buys and sells goods or services and in that process, earns money. With this logic, a business model is a qualitative instrument for strategizing how business should be done. With the rise of the internet in the early 1990s, how business is being conducted has changed immensely. Value creation and communication networks have spread around the globe and diversified partners and consumer segments. At the same time, due to this development, both value creation and the predictability of a business's success has risen to a new level of complexity. Meanwhile, the first conceptualisations of how companies conduct their businesses have appeared and the term business model has arisen (Zott et al. 2011) as a means of describing how a business now operates. In the pursuit of assisting companies maintain competitive advantage by means of understanding, comparing, assessing, predicting and changing the way of doing business, diverse 
and even controversial concepts and approaches to business models have emerged in their wake. Mayo and Brown focus on the operational content, i.e. strategic purpose of a business by stressing the "key interdependent systems that create and sustain a competitive business" (Mayo and Brown 1999, 18). Morris, Schindehutte and Allen, on the other hand, propose a level-decision-approach by framing the supra-levels 'foundation,' 'proprietary,' and 'rules' levels á six sub-levels to lead business decision-making and to ensure that the individual decisions that are made within the company are internally consistent (Morris et al. 2005, 729). The three supra-levels cover the main areas of managerial decision-making in a company that answer increasingly specific questions at each level. At the foundation level, such basic questions have to be answered, as, how, for whom and by means of what sources of advantages, is value created? Furthermore, how exactly is profit generated? Meanwhile the proprietary level focuses on how the aspects of the foundation level are handled best and most uniquely. Finally, on the rules level, entrepreneurs should create guidelines and operating rules on how to strategize the foundation and proprietary of ones' business (Morris et al. 2005, 730f.). Osterwalder and Pigneur developed a value-based approach, in which the term business model entails a description of "the rationale of how an organization creates, delivers and captures value" (Osterwalder and Pigneur 2013, 14). This economic point of view allows an entrepreneur to develop and describe their business with nine core elements that involve this approach. These elements range from specific customer segments, revenues and partnerships to value proposition, activities and costs. Their business model approach is currently one of the most popular approaches for describing, developing and analysing business models.

Facing global environmental and social challenges, concepts like the business model of Osterwalder and Pigneur have been refined so that they include the reduction of negative impacts and the increase of benefits to both environment and society. Especially industries that thrive from non-renewable resources and those that create value mostly by employing cheap labour, serve as huge drivers of ecological imbalances and social inequalities. Concepts of sustainable business models are juxtaposed against the idea of 'business as usual' as they are meant to reflect upon their sustainability strategies and goals while earning money or replacing monetary earnings by environmental or social benefits in general. In that process, the meaning of value and the stakeholders involved in the business are redefined to be oriented towards the social and environmental perspective. In practice, that means that sustainability is not only implemented as a voluntary guideline, but as a fundamental part of each value proposition, value creation and value capture activity.

Product Service System-based and Circular Economy-based business models are examples of wide-ranging transformative models that include a product's entire lifespan into their considerations and are therefore viewed as the most effective sustainable business models. Their approaches require a perspective that is shifted from profit-oriented to enhanced benefits or reduced negative effects on environment and society. 


\subsection{Product Service System-Based Business Models: Satisfaction, Functionality and Ownership}

The Product Service System (PSS) concept highlights the shift from traditional businesses based on the development and sale of physical products to a new business orientation based on functionalities and benefits delivered through a combination of products and services (Barquet 2015, 40f). Product Service Systems reflect on a long history of societal appreciation of service and ownership. After the world wars at the beginning of the 20th century, a noticeable development in the way people in the Western hemisphere organised their daily lives occurred which was interrelated with the changing socio-economic structures of that time. Domestic or commercial services like household servants or public laundry services were slowly replaced by self-service systems. In that process, a materialisation of services which is now fittingly represented by increasingly cheap goods like the washing machine, enabled households to complete housework at home without the help of external parties by buying a product instead of a service (Roy 2000, 291). Yet, all the while since the fifties, a convergence of product and service and a second reconfiguration of the product service-relation has taken place, which gives way to speculations about the renewed dematerialisation of the economic sphere and the emergence of a "new service economy in which profitability is based [...] on the provision of services to meet essential human needs" (Jackson 1996 quoted in Roy 2000, 292). Innovative combinations of products and services that can satisfy the same or even more needs than the product by itself, have appeared. In addition to car-sharing as a more prominent example of PSS, more unknown forms are beginning to enter the markets. Philips and Turntoo have, for example, created a PSS that sells light-per-lux and lightening systems with installation, maintaining and disposal, as an alternative to the ownership of lightening infrastructure, like cables and light bowls (Ellen MacArthur Foundation 2016). Those systems relieve the consumer of maintenance, insurance and disposal expenses while satisfying similar needs (in those cases transportation and light) as the original business model in which selling the product would have sufficed.

Tukker argued that beyond the rising numbers of researchers interested in this new set of PSS, such business models have attracted the attention of entrepreneurs once it became clear that characteristics and quality of a product were insufficient at holding onto a business's competitive advantage (Tukker 2015, 77). Designing and selling a combination of service and product now stands as a prominent value proposition. Manzini and Velozzi see "selling satisfaction instead of providing a product" (Manzini and Vezzoli 2003, 851) as the crucial element of PSS business models. Various benefits abound for companies, like reaching out to new market sectors (Allen Hu et al. 2012, 354). At the same time, consumers favour customised offers and the exemption from the responsibility for a product's end of life. In that vein then, PSS are not necessarily inherently sustainable, as there is no evidence that simply replacing product selling for service offer is sufficient for leading to more sustainable solutions (Evans et al. 2007, 4226). Of course, the lesser need for 
materials and resources during the manufacturing process on account of the higher span of consumers that can be reached with lesser products, the higher the efficiency employed. This might well therefore serve to reduce the negative effects on the environment. Yet this factor alone hardly suffices to qualify PSS as sustainable.

Following Tukker's classification of PSS-based business models, the conclusion can be drawn that the three main categories that are product-oriented services, use-oriented services and result-oriented services, all offer different opportunities but also include different limitations for the promotion of social and environmental well-being. Product-oriented PSS could optimise energy and resource consumption since service offers, e.g. as maintenance and repair, might increase the use phase of products. However, the traditional dynamic of selling as many products as possible and therefore causing negative environmental effects, remains firmly in place. Use-oriented PSS, which includes models of leasing, renting and pooling, might on the one hand lead to higher impacts due to less careful consumer behaviour, but on the other hand to extensive improvement of usage efficiency. The volume of impact reduction due to this efficiency increase varies between 30 and $50 \%$, in instances of car sharing, ski-renting, and laundry services and even up to $1000 \%$ for drilling rental services. An even higher share of environmental benefits could be offered by result-oriented PSS, as this can be completely detached from product-oriented concepts. Examples could be payment-per-service unit-business models, like pay-per-copy copy shops or catering services, where a result is offered instead of a product. These models break the link between profit and production volume and reduce the incentive for large-scale production volumes and the accompanying resource consumption. Producing less to satisfy the needs of the same amount of consumers can significantly reduce the overall material usage. Nevertheless, using less materials, i.e. more durable materials, could be an incentive for result-oriented services (Tukker 2015, 86). To facilitate the identification of sustainable practices, a special set of five sustainability factors of PSS (see Fig. 1) was created. In combination, they target not only the environmentally thoughtful handling of resources, but also social justice and change.

(1) Design for Environment (DFE) is meant to include all stages of a product's lifecycle by following strategies of minimizing material and energy consumption and the selection of low impact materials and energy-efficient systems. What's more, cleaner technologies and environmentally friendlier materials and optimised distribution systems should be used.

Principles of disassembly, upgrading and adaptability should likewise be considered as end-of-life strategies. (2) The identification of the value for each stakeholder should take into account that longer lifespanmight decrease production, but cost savings can occur due to the reduction of material, the incentivizing of extended PSS lifecycles, and the profitability of new services. (3) Promoting change in behaviour through educating consumers and PSS providers can help to overcome the high symbolic value attached to owning a product and thereby increase the involvement of the consumers and employees as well as the satisfaction 


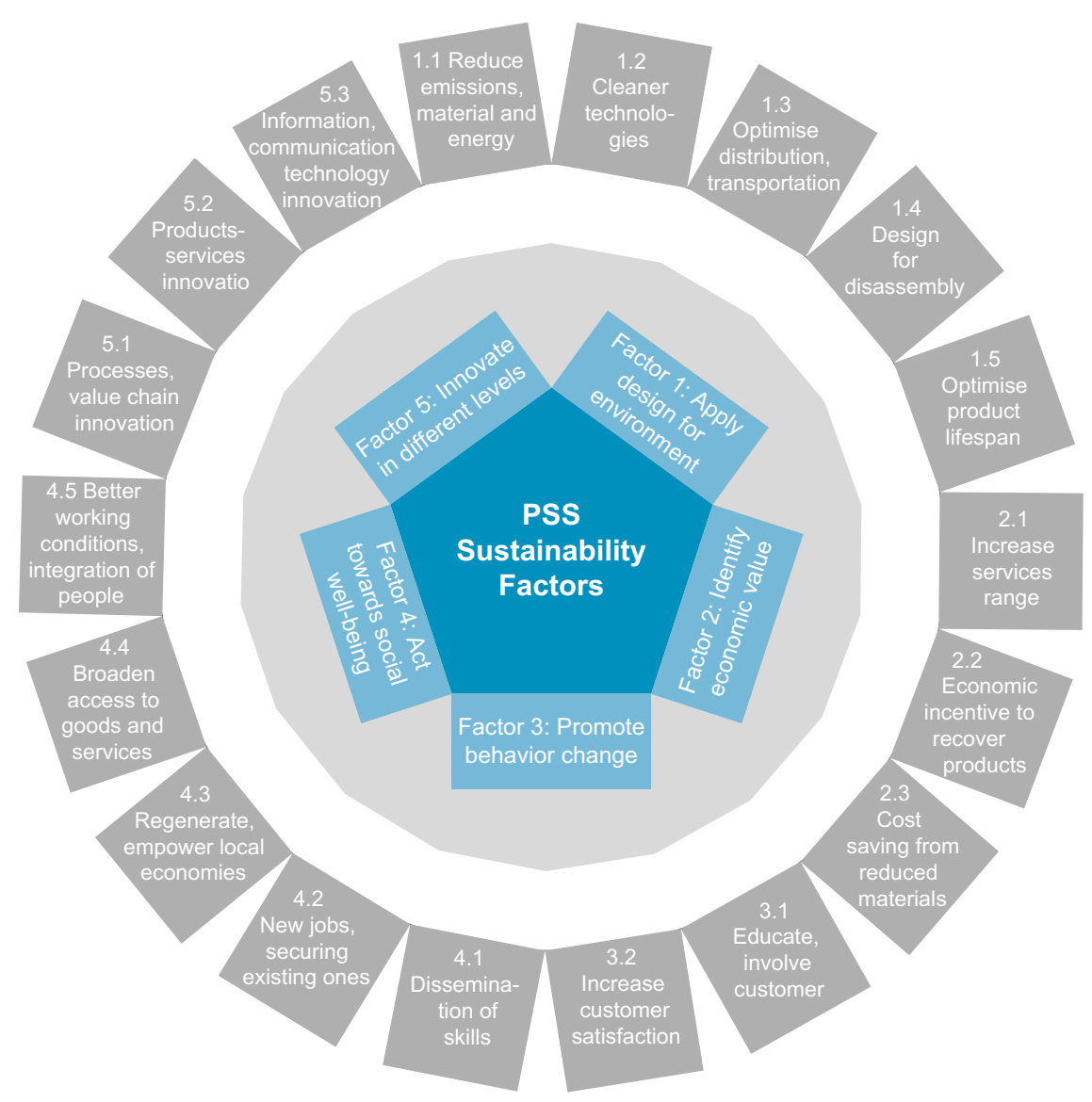

Fig. 1 Sustainability factors for product service systems

of the consumer's needs. Transparency, appearance, usability of the offer, price and time and cost saving can represent the means of this sustainability factor. As part of the (4) Delineation actions to social well-being, a PSS should also take responsibility for the creation and safety of jobs, for example, hiring and training employees to provide services. The fairness of the working-conditions (hours, wages, health and safety) and the tackling of social issues like the integration of social minorities or marginalised groups are also targets the attainment of sustainable PSSs. The empowerment of local communities and a broadened access to lower income segments should also constitute part of the actions for social well-being. (5) Innovation in different levels describes how innovations made in individual parts of the value chain might not be as sustainably successful as aligned and concentrated measures of innovation and optimisation. On-site assembly, remote controlling for maintenance and repair of products can be strategies for this factor (Barquet et al. 2016). 


\subsection{Zero-Waste or Reusable Waste: Circular Economic Business Models}

Similar in their relevance and prominence in sustainable manufacturing are concepts of a circular economy that are based on the idea of following a product's whole life cycle and reducing resource input, waste, emission and energy leakage. Using nature as a model that cycles all its materials by means of natural decomposition and recreation, as promoted by Industrial Ecology thinkers like Keneth Boulding, Robert Ayres, Allen Kneese and Robert Frosch, involves putting money and hope into a product's durability and zero-waste policies.

Walter Stahel was one of the first scholars who, by introducing his concept of Performance Ecology in the 1980s, broached the issue of a closed-loop economy. Product-life prolonging measures like recycling, reusing, upgrading and remanufacturing coupled with a PSS-like idea of selling performance rather than the product, were to become the characteristics of his idea of a self-replenishing economy. William McDonough and Michael Braungart introduced their Cradle to Cradle (C2C) framework in the 1990s in Germany, wherein they argue that focusing on emission reduction is the wrong determination, as, emissions are the inevitable consequence of living. Instead, economy should focus on what they call materials-in-the-wrong-place-problems. Products should be designed and manufactured so that their materials could either be safely transformed in biological systems (biological nutrients), or be indefinitely recycled (technical nutrients), in case of substances that cannot be absorbed by nature. In the end, a cycled economy forms on account of the healthy waste that turns one process's waste into another process's resource. The Blue Economy as conceptualised by Gunther Pauli also stresses the importance of the question of how to create value from waste as a mean of providing for people's basic needs. The 2012 World Economic Forum shed new light on the idea of Circular Economy since the Ellen MacArthur Foundation introduced their publication Towards the Circular Economy and therein caused re-examination of previous ideas with a similar focus (Brennan et al. 2015, 223f).

A study of literature on circular business models (CBM) shows that they are generally considered to be sustainable. Five factors compounded out of 16 sub-factors seem to be critical for benefitting the environment and society while generating economic profit at the same time (see Fig. 2): (1) Resource optimization targets the saving of material, use of material and energy from renewable resources, dematerialisation, the creation of value from formerly considered waste and the creation of more value from each unit of resource (World Economic Forum 2014; Ellen MacArthur Foundation 2013a, b; Low et al. 2016; Geng et al. 2016; Schulte 2013; Winkler 2011; Guohui and Yunfeng 2012; Romero and Noran 2015). (2) Improve environmental capabilities consists of the reduction of negative emissions into the environment while increasing positive emissions to foster e.g. soil health and land productivity (World Economic Forum 2014; Ellen MacArthur Foundation 2013a, b). (3) Risk reduction and control can be achieved through design for 


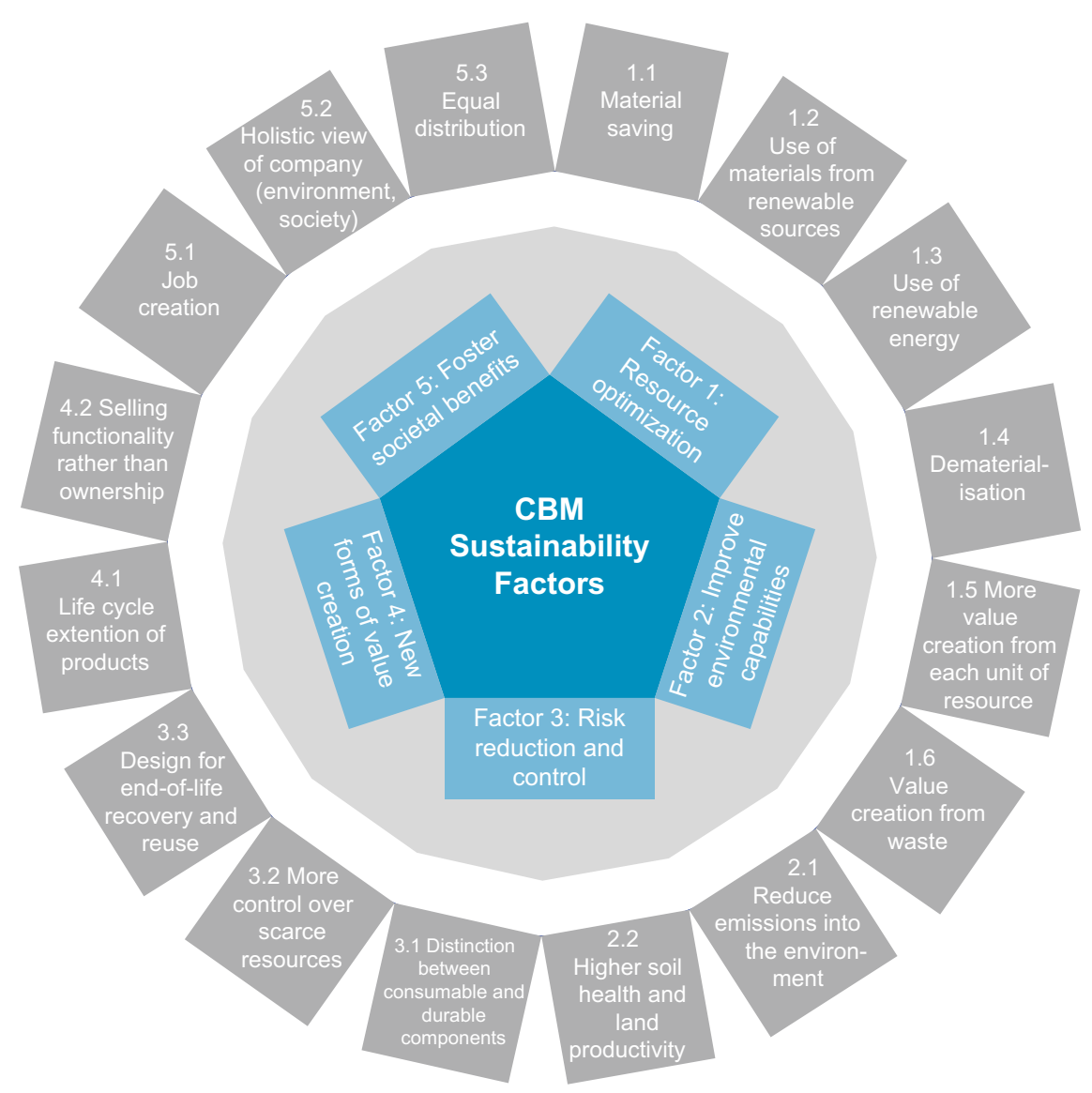

Fig. 2 Sustainability factors for circular business models

end-of-life recovery and reuse, whereby more control over scarce resources and a distinction between consumable and durable components can be attained (World Economic Forum 2014; Ellen MacArthur Foundation 2013a, b). (4) New forms of value creation can be reached by increasing the products' longevity, which then can foster new forms of consumption such as pay-per-use instead of ownership (Schulte 2013). (5) Finally, circular economic business models can foster societal benefits by creating new jobs, fostering equal distribution by fair wages and social thoughtful distribution of job opportunities, as well as by means of their holistic view of the company with regards to the environment and society (World Economic Forum 2014; Ellen MacArthur Foundation 2013b; Siemieniuch et al. 2015). 


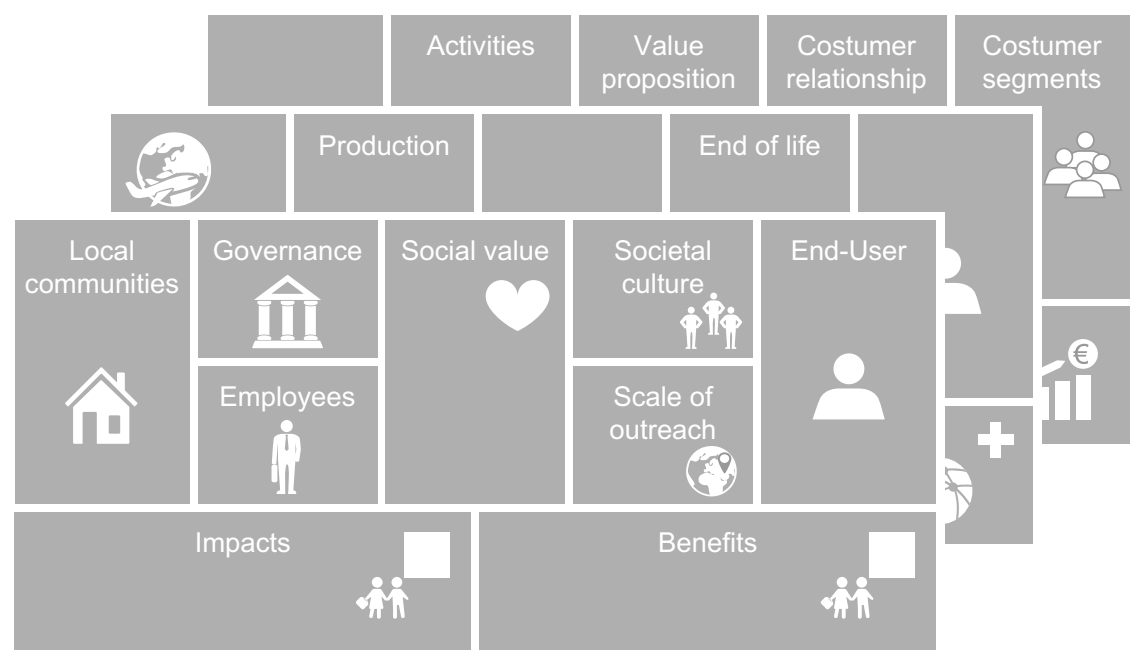

Fig. 3 Section of the three layered canvas business model tool (Joyce et al. 2015)

\section{Developing Sustainable Business Models}

Sustainable business model tools were developed to either adapt conventional business models or design new ones so that they fulfil the purpose of creating business that are environmentally and socially friendly as well as economically sufficient. Osterwalder and Pigneur developed the most common tool for business model design, called Canvas. In drawing up the nine core elements of their business model approach that was mentioned above (Costumer Segments, Channels, Costumer Relationship, Revenues, Value Proposition, Resources, Activities, Partners and Costs), entrepreneurs can easily conceptualise their business model (Osterwalder and Pigneur 2013). Criticism from environmentally and socially concerned academics and economists targets the focus on the economic perspective and benefits to the disadvantage of environmental and social issues. To meet this demand, the three layered Canvas (see Fig. 3) was later developed.

\subsection{The (Three Layered) Canvas: A Tool for Sustainable Business Model Creation}

Starting out with the idea that businesses will be more sustainable and also economically more successful when their business model innovations take a triple bottom line approach "people, planet and profit", as John Elkington imagined it in 1998, Joyce, Paquin and Pigneur designed a triple layered canvas that takes both 
economic, social and environmental benefits and impacts into account (Joyce et al. 2015).

The authors used elements of Environmental Life Cycle Assessment to create the environmental layer of their concepts, which now include Functional Value, Materials, Production, Supplies and Outsourcing, Distribution, Use Phase, End-of-Life, Environmental Impacts and Environmental Benefits. Using a Stakeholder approach, they designed the nine elements of their social layer (Social Value, Employees, Governance, Local Communities and Suppliers, Societal Culture, Scale of outreach, End-Users, Social Impacts and Social Benefits). Vertical coherence enables the comparison and analysis of interaction and interference of specific elements, like for example value proposition, functional value and social value (Joyce et al. 2015).

\subsection{Business Model Innovation Meets Future Studies}

The desire to know the future can be observed continuously throughout time. Independent of geographic or cultural boundaries, the practices range from highly spiritual (divination or prophecy) to purely scientific (probability calculation or game theory), and build hybrid forms like Utopian concepts in the arts or social sciences. After the Second World War, scientific future studies took a turn to what is now called modern future studies (Son 2015, 122f.). Scenario planning was introduced in the 1950s as a method of demonstrating the extremes and a variety of hypothetical futures, and in that pursuit, a shift from forecasting to the manageability of the outcome with present measures emerged (Son 2015, 124). Nowadays, scenario planning is used as a tool for describing possible future outcomes and situations based on a complex net of influence factors. A fragmentation of future studies brought a variation of approaches and goals, such as explorative or normative scenarios (Bradfield et al. 2005). Abele and Reinhart, for example, created explorative scenarios for the German manufacturing industry in 2020 and described possible futures surrounding fields in which a high level of adaptability and competitiveness with regards to the global markets is required (Abele and Reinhart 2011). Using the pathways for sustainable technology development approach by Gausemeier, their findings were used to deduce the concept of a highly modern and versatile factory based on modular machine tools, the so-called "Living Factory" (see Fig. 4) (Gausemeier 2014). A Living Factory involves high versatility and mobility of production facilities that can be reached through the combination of modular machine tool frames, so-called $\mathrm{LEG}^{2} \mathrm{O}$ frames, and business model innovation that makes use of a Product Service System and circular business model concepts. A detailed description and analysis of the $\mathrm{LEG}^{2} \mathrm{O}$ frame is presented in the part Sustainability-driven development of manufacturing technologies in this book. Lightweight constructed and accuracy-tuned modular machine tools enable partial replacement and flexible combination. Applying a PSS-based system might mean renting or leasing the machine-modules, which are in the best case provided 


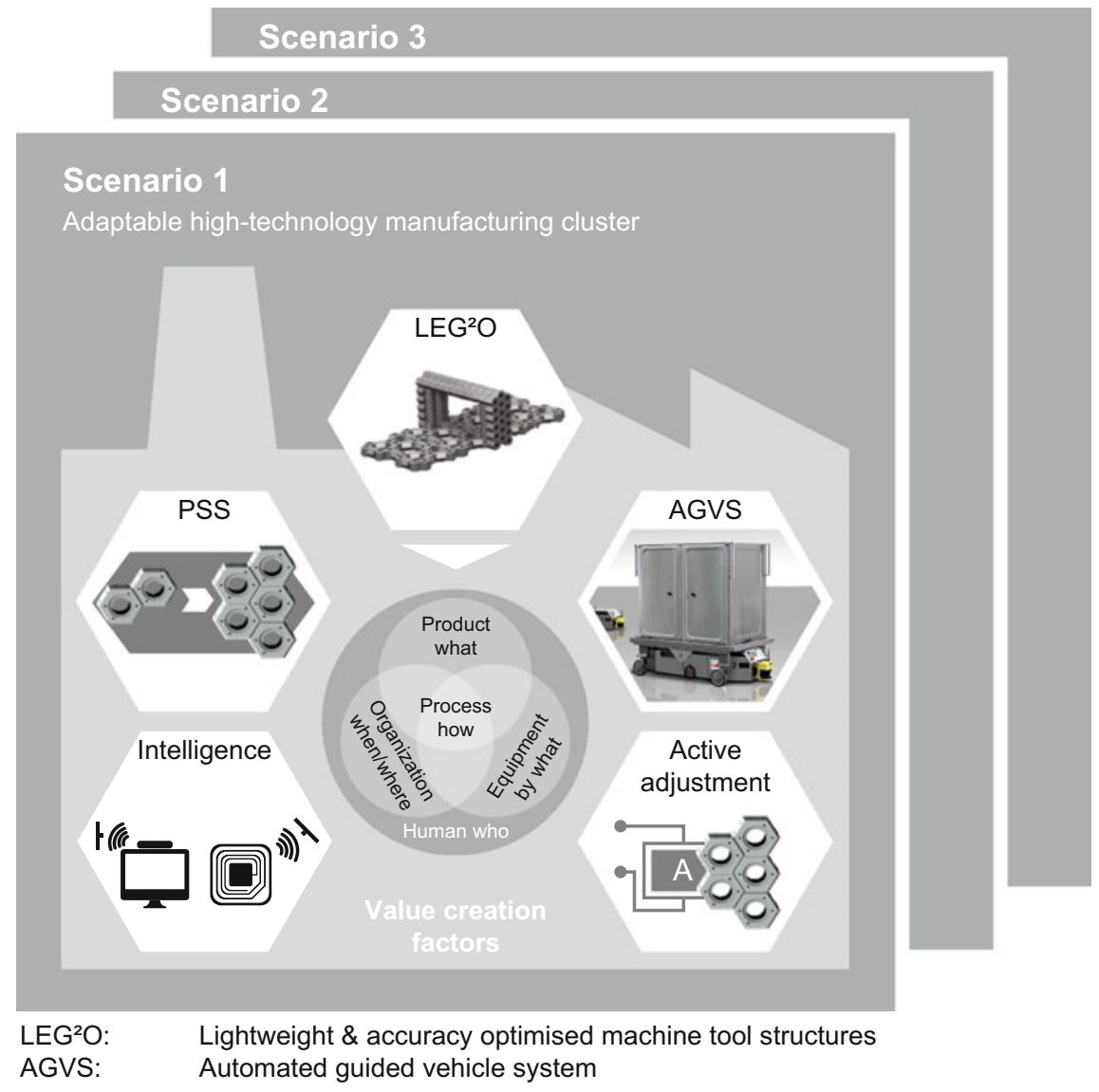

Fig. 4 Excerpt of an abstract representation of the living factory

according to the principles of a circular economy, along the lines of occupancy and requirement. A Living Factory can therefore adapt itself to fluctuations in demand and environmental and social conditions. Intelligent communication and information technology is used, including RFID tags and automated guided vehicles for logistics. Specifically, this means to reach a circular system in which machine-modules are offered by means of a central technology provider who can assist in building up the initial modular machines, and later on extend on them by adding additional building blocks, or updating them with new functionalities and smart blocks. Similarly, unused building blocks can then be taken back to be transferred to another customer. Outdated building blocks, meanwhile, can be updated, remanufactured or recycled for material recovery by the central technology provider. 


\section{Conclusion and Outlook}

Business models such as Product Service Systems (PSS) and Circular Business Models (CBM), offer great potential for changing manufacturing according to the triple-bottom line approach of producing benefits for society, environment and economy and at the same time minimizing negative effects. However, the application of those business models will not necessarily fulfil economic, environmental and social needs. Adherence to such factors like the ones that were presented in this chapter, is nevertheless essential if a truly sustainable business model is to be created. Yet, getting to know these factors might stimulate enterprises not only to adopt sustainable business models, but also to implement sustainable practices and solutions.

Scenario planning can be seen as a useful tool for theoretically predicting the future's needs along with the success of a business model. The complex challenges that businesses and sustainability will face are well advised to be included in current business model innovation in pursuit of enhancing sustainability success and reducing risk of failure. Business model innovation and sustainable technology development mark the two major fields that require scientific progress, as, sustainable business models indeed rely heavily on both aspects. Both also include new ideas in the structuring of manufacturing processes as the example of the Living Factory shows. Modular machine-tools that are themselves produced and used according to circular principles need to be developed and tested. The transition from traditional business models to sustainable ones and how methods from future studies, e.g. scenario planning, can support these transitions are, furthermore, relevant subjects demanding deeper investigation. Another important aspect lies in the creation of indicators to measure the sustainability of business models. Building on the predominantly qualitative factors of developing quantitative approaches, has yet to be explored. The adoption of PSS and circular economy principles, moreover, can facilitate yet hardly guarantee that this version of business practice will result in a more sustainable performance. The need for future research likewise extends to the management of remanufacturing and (re-)consumption, which specifically requires a more transdisciplinary approach.

\section{References}

Abele, E., and G. Reinhart. 2011. Zukunft der Produktion: herausforderungen, forschungsfelder, chancen. München: Carl Hanser Verlag.

Allen Hu, H., S.H. Chen, C.W. Hsu, C. Wang, and C.L. Wu. 2012. Development of sustainability evaluation model for implementing product service systems. International Journal Environment Sciences Technology 9(2): 343-354. doi:10.1007/s13762-012-0037-7.

Barquet, Ana P. 2015. Creation of product-service systems (PSS) proposals in the fuzzy front-end. PhD dissertation, University of São Paulo, Brazil.

Barquet, Ana P., Johannes Seidel, Günther Seliger, and Holger Kohl. 2016. Sustainability factors for PSS business models. Procedia CIRP 47: 436-441. doi:10.1016/j.procir.2016.03.021. 
Bradfield, Ron, George Wright, George Burt, George Cairns, and Kees van der Heijden. 2005. The origins and evolution of scenario techniques in long range business planning. Futures 37(8): 795-812. doi:10.1016/j.futures.2005.01.003.

Brennan, Geraldine, Mike Tennant, and Fenna Blomsma. 2015. Business and production solutions: Closing loops and the circular economy. In Sustainability. Key Issues, 219-239.

Ellen MacArthur Foundation. 2013a. Towards the circular economy: Economic and business rationale for an accelerated transition.

Ellen MacArthur Foundation. 2013b. Towards the circular economy: Opportunities for the consumer goods sector.

Ellen MacArthur Foundation. 2016. Selling Light as a Service. https://www. ellenmacarthurfoundation.org/case-studies/selling-light-as-a-service.Accessed 02 Aug 2016.

Evans, Stephen, J. Paulo Partidário, and Joanna Lambert. 2007. Industrialization as a key element of sustainable product-service solutions. International Journal of Production Research 45(1819): 4225-4246. doi:10.1080/00207540701449999.

Gausemeier, P. 2014. Nachhaltige Technologiepfade für unterschiedliche Entwicklungsniveaus. $\mathrm{PhD}$ dissertation, Technische Universität Berlin.

Geng, Yong, Tsuyoshi Fujita, Hung-suck Park, Anthony S. Chiu, and Donald Huisingh. 2016. Recent progress on innovative eco-industrial development. Journal of Cleaner Production 114: 1-10. doi:10.1016/j.jclepro.2015.09.051.

Guohui, Song, and Li Yunfeng. 2012. The effect of reinforcing the concept of circular economy in west china environmental protection and economic development. Procedia Environmental Sciences 12: 785-792. doi:10.1016/j.proenv.2012.01.349.

Joyce, Alexandre, Raymond Paquin, and Yves Pigneur. 2015. The triple layered business model canvas. A tool to design more sustainable business models. In ARTEM organizational creativity international conference, Nancy, France.

Low, Jonathan S.C., Tobias B. Tjandra, Wen F. Lu, and Hui M. Lee. 2016. Adaptation of the product structure-based integrated life cycle analysis (psila) technique for carbon footprint modelling and analysis of closed-loop production systems. Journal of Cleaner Production 120: 105-123. doi:10.1016/j.jclepro.2015.09.095.

Manzini, E., and C. Vezzoli. 2003. A strategic design approach to develop sustainable product service systems: Examples taken from the 'environmentally friendly innovation' Italian prize. Journal of Cleaner Production 11(8): 851-857. doi:10.1016/S0959-6526(02)00153-1.

Mayo, Michael, and Gordon Brown. 1999. Building a competitive business model. Ivey Business Journal 63(3): 18-23.

Morris, Michael, Minet Schindehutte, and Jeffrey Allen. 2005. The entrepreneur's business model: Toward a unified perspective. Journal of Business Research 58(6): 726-735. doi:10.1016/j. jbusres.2003.11.001.

Osterwalder, Alexander, and Yves Pigneur. 2013. Business model generation: A handbook for visionaries, game changers, and challengers, 1st ed. Hoboken, NJ: Wiley.

Romero, David, and Ovidiu Noran. 2015. Green virtual enterprises and their breeding environments. Engineering their sustainability as systems of systems for the circular economy. IFAC-PapersOnLine 48(3): 2258-2265. doi:10.1016/j.ifacol.2015.06.424.

Roy, Robin. 2000. Sustainable product-service systems. Futures 32: 289-299.

Schulte, Uwe G. 2013. New business models for a radical change in ressource efficiency. Environmental Innovation and Societal Transitions 9: 43-47. doi:10.1016/j.eist.2013.09.006.

Siemieniuch, C.E., M.A. Sinclair, and M.J.d. Henshaw. 2015. Global drivers, sustainable manufacturing and systems ergonomics. Applied Ergonomics 51: 104-19. doi:10.1016/j. apergo.2015.04.018.

Son, Hyeonju. 2015. The history of Western futures studies: An exploration of the intellectual traditions and three-phase periodization. Futures 66: 120-137. doi:10.1016/j.futures.2014.12. 013.

Tukker, Arnold. 2015. Product services for a resource-efficient and circular economy — a review. Journal of Cleaner Production 97: 76-91. doi:10.1016/j.jclepro.2013.11.049. 
Winkler, H. 2011. Closed-loop production systems - a sustainable supply chain approach. CIRP Journal of Manufacturing Science and Technology 4(3): 243-246. doi:10.1016/j.cirpj.2011.05. 001.

World Economic Forum. 2014. Towards the circular economy: Accelerating the scale-up across global supply chains. Geneva.

Zott, Christoph, Raphael Amit, and Lorenzo Massa. 2011. The business model: Recent developments and future research. In Journal of Management 37: 1019-1042.

Open Access This chapter is licensed under the terms of the Creative Commons Attribution 4.0 International License (http://creativecommons.org/licenses/by/4.0/), which permits use, sharing, adaptation, distribution and reproduction in any medium or format, as long as you give appropriate credit to the original author(s) and the source, provide a link to the Creative Commons license and indicate if changes were made.

The images or other third party material in this chapter are included in the book's Creative Commons license, unless indicated otherwise in a credit line to the material. If material is not included in the book's Creative Commons license and your intended use is not permitted by statutory regulation or exceeds the permitted use, you will need to obtain permission directly from the copyright holder. 